\title{
Michael Theunissen
}

Selbstverwirklichung und Allgemeinheit 



\title{
Michael Theunissen
}

\section{Selbstverwirklichung und Allgemeinheit}

\author{
Zur Kritik
}

des gegenwärtigen Bewußtseins

Walter de Gruyter · Berlin · New York 1982 


\section{Theunissen, Michael:}

Selbstverwirklichung und Allgemeinheit : zur Kritik d. gegenwärtigen Bewusstseins / Michael Theunissen. - Berlin ; New York : de Gruyter, 1981.-

ISBN 3-11-008781-2

1981 by Walter de Gruyter \& Co., vormals G. J. Goschen'sche Verlagshandlung · J. Guttentag, Verlagsbuchhandlung - Georg Reimer Kar! J. Trübner - Veit \& Comp., Berlin 30, Genthiner Straße 13. Alle Rechte, insbesondere das der Übersetzung in fremde Sprachen, vorbehalten. Ohne ausdrückliche Genehmigung des Verlages ist es auch nicht gestattet, dieses Buch oder Teile daraus auf photomechanischem Wege (Photokopie, Mikrokopie, Xerokopie) zu vervielfältigen.

Printed in Getmany

Satz: H. Hagedorn, Berlin Druck: Hass \& Co, Berlin - Buchbinderarbeiten: Fuhrmann, Berlin 